\title{
Alternating offers with asymmetric information and the unemployment volatility puzzle
}

\author{
Pierrick Clerc ${ }^{1}$ \\ Banque de France, 31 rue Croix des Petits Champs, Paris, 75001 France
}

\section{A R T I C L E I N F O}

\section{JEL classification}

E 24

E 32

J63

$\mathrm{J} 64$

\section{Keywords:}

Unemployment and vacancies volatility

Wage bargaining

Wage rigidity

\begin{abstract}
A B S T R A C T
To provide micro-founded real wage rigidities, the literature on the unemployment volatility puzzle has considered alternating offers on one side, and asymmetric information on the other. Separately, however, these two frameworks deliver a limited amount of wage stickiness and thus require questionable calibrations to raise unemployment fluctuations. In this paper, we argue that the alternating offers model with one-sided asymmetric information, which combines the two frameworks, gives a more satisfactory answer to the puzzle. The results are improved along two dimensions. First, we show that this model is capable to generate large unemployment movements for a realistic calibration. Secondly, the model produces a right degree of real wage pro-cyclicality for such a calibration and therefore delivers a micro-founded explanation to real wage rigidities.
\end{abstract}

(C) 2017 Elsevier B.V. All rights reserved.

\section{Introduction}

The incapacity of the canonical search-and-matching model to replicate labor market dynamics has triggered a substantial literature. Among the myriad of solutions proposed to solve this "unemployment volatility puzzle" raised by Shimer (2005), real wage rigidities have received the most attention. In order to give micro-foundations to real wage stickiness, the literature related to this puzzle has investigated mainly two ways: alternating wage offers (Hall and Milgrom, 2008) and asymmetric information during the wage bargaining (Kennan, 2010). These two frameworks, however, display only a weak amount of wage stickiness and therefore need questionable calibrations to amplify unemployment fluctuations. Particularly, very high labor shares and large additional hiring costs are required to reproduce the volatility of the unemployment rate in the United States. In this paper, we argue that the alternating offers model with one-sided asymmetric information, which combines the two frameworks, provides a more satisfactory answer to the puzzle pointed out by Shimer. Notably, the higher degree of wage stickiness makes this model able to produce large unemployment movements for realistic labor shares and without assuming additional costs for firms.

The alternating offers model with one-sided asymmetric information (henceforth "AOMOSAI") initially considers a seller of an item and a potential buyer who bargain over the item's price. Both parties alternate in making proposals in a Rubinstein (1982) fashion. Moreover, information is asymmetric since the seller's valuation is common knowledge whereas the buyer's valuation is known only to herself. In such a framework, there is a multiplicity of equilibria which explains that a literature was addressed to narrow down the range of predicted bargaining outcomes. Grossman and Perry (1986) and Gul et al. (1986) develop respectively the concepts of stationary equilibrium and perfect sequential equilibrium. Gul and Sonnenschein (1988) refine the conditions over strategies and time interval between successive offers that ensure a single equilibrium.

The wage bargaining is a natural implementation of that framework. In this case, the worker and the employer alternate in making wage proposals but the productivity of the match is observed only by the employer. Within this set-up, Menzio (2007) determines the conditions under which vague non-contractual statements (found in help wanted ads) by the firms are correlated to actual wages and partially direct the search strategy of the workers. However, the AOMOSAI was not considered by the large literature that follows the seminal paper by Shimer (2005) on the unemployment volatility puzzle. Instead, this literature focuses on each component separately, i.e. alternating offers on one hand, and asymmetric information on the other.

In the canonical search-and-matching model, the real wage is determined by the standard Nash Bargaining for which information is perfect and the threat points of the parties are their pro-cyclical outside options. The resulting real wage is thus flexible with respect to both labor productivity and labor-market conditions. Hall and Milgrom (2008) replace

E-mail addresses: pierrick.clerc@banque-france.fr, pierrick.clerc@live.fr

1 I would thank Florin Bilbiie, Jordi Galí, Jean-Olivier Hairault, Keith Kuester, François Langot, Guido Menzio, Franck Portier and Etienne Wasmer for helpful comments. The views expressed here are these of the author alone and not of Banque de France. 
the Nash Bargaining by the Alternating Offers Bargaining. They point out that on a frictional labor market, the pro-cyclical outside options are not credible threat points. The credible threat points in a sequential bargaining are the a-cyclical payments obtained during the bargaining, which implies some rigidity of the real wage with respect to labormarket conditions. The Asymmetric Information Game was investigated by Kennan (2010). Firms would be subject to both aggregate and specific productivity shocks and the latter are supposed to be pro-cyclical. It is also assumed that only employers are able to observe the specific productivity component. Kennan shows, in a generalization of the Nash Bargaining to cases with private information, that it is rational for workers to be prudent by considering that the specific productivity is the lowest. The bargained real wage is therefore insensitive to the larger number of matches realizing a high specific productivity in cyclical booms, and then delivers some rigidity with respect to labor productivity.

In this paper, we stress that the Alternating Offers Bargaining and the Asymmetric Information Game, separately, display only a limited real wage stickiness. These frameworks thus require implausible calibration values, most notably labor shares much higher than their empirical counterpart and large additional hiring and training costs, to amplify labor-market fluctuations. We show that once these models are calibrated to match the empirical labor share in the US, and without additional costs, the volatility of the labor market collapses. By combining the two frameworks, the AOMOSAI brings a higher level of wage stickiness that considerably magnifies the labor-market response to aggregate shocks. The results are improved along two dimensions. First, the model almost completely replicates unemployment volatility when calibrated to match the empirical labor share, and without assuming additional costs. Secondly, the model produces a right amount of pro-cyclicality for the real wage with this calibration and then provides a micro-founded explanation of the real wage rigidities which characterize labor markets.

The rest of this paper is organized as follows. In the next section, we derive the equations of the model. In Section 3, we calibrate and assess its quantitative properties. Section 4 concludes.

\section{The alternating offers model with one-sided asymmetric information}

\subsection{The basic structure}

We consider an economy populated by a continuum of workers and a continuum of firms with measures 1 . Every agent is risk-neutral and has a life of indefinite length. The current state is denoted by $i$. A job match of type $j$ produces an output at flow rate $p_{i}+y_{j}$, where $p_{i}$ is an aggregate component common to all matches, and $y_{j}$ is a random idiosyncratic variable drawn from a commonly known state varying $\operatorname{CDF} F_{i}(y)$ that has strictly positive density $f_{i}(y)$ over the fixed interval $\left[y_{L}, y_{H}\right]$, with $y_{L}>0$ and $\int_{y_{L}}^{y_{H}} f_{i}(y) d y=1$.

We assume that there is a positive covariance between $p_{i}$ and the average (or expected) idiosyncratic productivity $\int_{y_{L}}^{y_{H}} y f_{i}(y) d y$, which is an important feature of Kennan (2010). This positive covariance means that the average idiosyncratic productivity is pro-cyclical: during an economic expansion, there is an improvement in the distribution of the idiosyncratic productivity and the amount of matches with higher types increases. Kennan (2010) gives some evidence ${ }^{2}$ that supports this assumption.

The average value of total productivity (henceforth the "average productivity") in this economy at state $i$ is given by:

$\rho_{i}=p_{i}+\int_{y_{L}}^{y_{H}} y f_{i}(y) d y$

Following a positive shock on aggregate productivity, $\rho_{i}$ rises both because $p_{i}$ and the proportion of matches with higher types increase. Note that $\rho_{i}$ is the productivity that we observe in the empirical data.

${ }^{2}$ From Dunne et al. (2004).
The rest of the framework is analogous to the standard search and matching model. The opportunity cost of employment to the worker and the cost of posting a vacancy to a firm are denoted by $z$ and $c$, respectively. The number of new matches each period is given by a matching function $m\left(u_{i}, v_{i}\right)$, where $u_{i}$ and $v_{i}$ represent the number of unemployed workers and the number of open job vacancies, respectively. Since the number of workers is normalized to $1, u_{i}$ and $v_{i}$ also represent the unemployment and vacancy rates. The job-finding rate $f\left(\theta_{i}\right)=\frac{m\left(u_{i}, v_{i}\right)}{u_{i}}=$ $m\left(1, \theta_{i}\right)$ is increasing in market tightness $\theta_{i}$, the ratio of vacancies to unemployment. The rate at which vacancies are filled is denoted by $q\left(\theta_{i}\right)=\frac{m\left(u_{i}, v_{i}\right)}{v_{i}}=\frac{f\left(\theta_{i}\right)}{\theta_{i}}$, and is decreasing in $\theta_{i}$. The form of the matching function is assumed to be Cobb-Douglas, with $m\left(u_{i}, v_{i}\right)=m_{0} u_{i}^{\eta} v_{i}^{1-\eta}$. This implies $f\left(\theta_{i}\right)=m_{0} \theta_{i}{ }^{1-\eta}$ and $q\left(\theta_{i}\right)=m_{0} \theta_{i}{ }^{-\eta}$. Finally, matches are destroyed at the exogenous rate $s$ and all agents have the same discount rate $r$.

We denote by $U_{i}$ the value of unemployment, $W_{i j}$ the worker's value of a match of type $j, J_{i j}$ and $V_{i j}$ the employer's values of a filled job and a vacancy of type $j$, respectively. All these values are determined by the Bellman equations:

$r U_{i}=z+f\left(\theta_{i}\right)\left(W_{i j}-U_{i}\right)+\lambda\left(E_{i} U_{i^{\prime}}-U_{i}\right)$

$r W_{i j}=w_{i}\left(y_{j}\right)-s\left(W_{i j}-U_{i}\right)+\lambda\left(E_{i} W_{i^{\prime} j}-W_{i j}\right)$

$r J_{i j}=p_{i}+y_{j}-w_{i}\left(y_{j}\right)-s J_{i j}+\lambda\left(E_{i} J_{i^{\prime} j}-J_{i j}\right)$

$r V_{i j}=-c+q\left(\theta_{i}\right)\left(J_{i j}-V_{i j}\right)+\lambda\left(E_{i} V_{i^{\prime} j}-V_{i j}\right)$

where $\lambda$ represents the arrival rate of aggregate productivity shocks and $E_{i}$ the expectation operator conditional on the current state $i$.

Free entry is assumed on the goods market, such that the expected profit of opening a vacancy is zero $\left(V_{i j}=0\right)$. For a type $j$ match, the zero-profit condition is:

$\frac{c}{q\left(\theta_{i}\right)}=\frac{p_{i}+y_{j}-w_{i}\left(y_{j}\right)+\lambda E_{i} J_{i^{\prime} j}}{r+s+\lambda}$

For the whole economy, this condition is:

$\frac{c}{q\left(\theta_{i}\right)}=\frac{\rho_{i}-\omega_{i}+\lambda E_{i} J_{i^{\prime}}}{r+s+\lambda}$

with $\omega_{i}$ the average wage (the wage observed in the data) given by:

$\omega_{i}=\int_{y_{L}}^{y_{H}} w_{i}(y) f_{i}(y) d y$

Wages are assumed to be renegotiated after every aggregate shock, so the real wages determined in the next subsection only depend on the current state $i$.

\subsection{The wage bargaining}

Nash Bargaining. Before Shimer (2005), the Nash Bargaining was traditionally applied by the search-and-matching literature to get the real wage. In this case, the equilibrium wage is determined by the Generalized Nash Solution with the outside options as threat points. The outside options are $U_{i}$ for the worker and $V_{i j}=0$ for the employer. The surplus (in flow rates) of the worker for a type $j$ match is therefore $w_{i}\left(y_{j}\right)-r U_{i}$ while the surplus of the employer for the same match is $p_{i}+y_{j}-w_{i j}$. Denoting by $\beta$ the worker's bargaining power, the real wage of a type $j$ match is:

$w_{i}^{N B}\left(y_{j}\right)=(1-\beta) z+\beta\left(p_{i}+y_{j}+c \theta_{i}\right)$

The average wage is:

$\omega_{i}^{N B}=(1-\beta) z+\beta\left(\rho_{i}+c \theta_{i}\right)$ 
Asymmetric Information Game. In the Asymmetric Information Game considered by Kennan (2010), it is assumed that only employers are able to observe the type of each match. Workers know the distribution of $y$ over $\left[y_{L}, y_{H}\right]$, but they are unable to observe the types of the matches. Kennan applies the Myerson (1984) neutral bargaining solution, which is a generalization of the Nash Bargaining to the case of imperfect information. He shows that it is rational for workers to bargain under the assumption that the match's type is the lowest. With such a strategy, a given worker avoids to lose the match, which would be the outcome if the match's type was lower than the type considered by the worker. Whatever the type of the match, the equilibrium wage is then the real wage resulting the Nash Bargaining over the lowest surplus, $w_{i}^{N B}\left(y_{L}\right)$. The average wage in the Asymmetric Information Game is therefore:

$\omega_{i}^{A I G}=w_{i}^{N B}\left(y_{L}\right)=(1-\beta) z+\beta\left(p_{i}+y_{L}+c \theta_{i}\right)$

There is only one difference between Eqs. (8) and (9): in Eq. (8), it is the average productivity $\left(\rho_{i}\right)$ which drives $\omega_{i}^{N B}$, while in Eq. (9), it is instead the productivity of the lowest type $\left(p_{i}+y_{L}\right)$ which drives $\omega_{i}^{A I G}$. Recall that a positive covariance between the aggregate productivity and the average idiosyncratic productivity is assumed. When the aggregate productivity increases, $\rho_{i}$ rises because both $p_{i}$ and the proportion of matches with higher types increase. Rather, $p_{i}+y_{L}$ rises only through the increase in $p_{i}$. The productivity which drives $\omega_{i}^{A I G}$ is thus less procyclical than the productivity which drives $\omega_{i}^{N B}$. Hence, the average wage resulting from the Asymmetric Information Game is less pro-cyclical than the one resulting from the Nash Bargaining.

Alternating Offers Bargaining. In the sequential wage bargaining considered by Rubinstein (1982) and Binmore et al. (1986), information over the type of each match is perfect. Workers and employers are assumed to make offers alternately until they reach an agreement. After a proposer makes an offer, the responding party has three options:

(i) accept the current proposal;

(ii) reject this proposal and make a counter-offer next period. During the period, the worker receives $z$ while it is assumed that the employer incurs a fixed cost $\gamma$. The payoffs $z$ and $-\gamma$ are called the disagreement payoffs;

(iii) abandon the negotiation and take her outside option, i.e. $U_{i}$ for the worker and $V_{i j}=0$ for the employer.

Hall and Milgrom (2008) argue that on a frictional labor market (with $f\left(\theta_{i}\right)<1$ ), both the worker and the employer gain more by going to the end of the bargaining process rather than leaving it to take the outside options. The threat to leave the wage bargaining is then not credible. The only credible threat is to delay it.

In order to determine the equilibrium wage, we apply the main result of Binmore et al. (1986): whenever the time interval between successive offers is sufficiently small, the solution of the Alternating Offers Bargaining converges to the solution of the corresponding static game. ${ }^{3}$ The solution to this game is found by the Generalized Nash Solution with the credible threat points. The credible threat points are not the outside options but the payments the players obtain when the bargain is delayed, i.e. the disagreement payoffs $z$ and $-\gamma$. The surplus (in flow rates) of the worker for a type $j$ match is therefore $w_{i}\left(y_{j}\right)-z$ while the surplus of the employer for the same match is $p_{i}+y_{j}-w_{i j}+\gamma$. Hence, the real wage for a type $j$ match in this Alternating Offers Bargaining is:

$w_{i}^{A O B}\left(y_{j}\right)=(1-\beta) z+\beta\left(p_{i}+y_{j}+\gamma\right)$

The average wage is:

$\omega_{i}^{A O B}=(1-\beta) z+\beta\left(\rho_{i}+\gamma\right)$

3 Mortensen and Nagypál (2007), Jung and Kuester (2011) and Faia et al. (2014) follow the same strategy to determine the real wage.
Again, there is only one difference between Eqs. (8) and (10): in Eq. (8), $\omega_{i}^{N B}$ depends on labor-market conditions through $\theta_{i}$, whereas in Eq. (10), $\omega_{i}^{A O B}$ is insulated from these conditions but instead depends on the fixed cost $\gamma$. This reflects the fact that the threat points for the Alternating Offers Bargaining are no longer the pro-cyclical outside options but instead the a-cyclical disagreement payoffs. Therefore, the average wage resulting from the Alternating Offers Bargaining is also less pro-cyclical than the one resulting from the Nash Bargaining.

AOMOSAI. The AOMOSAI involves the introduction of asymmetric information into the Alternating Offers Bargaining. As in the Asymmetric Information Game, it is assumed that employers can observe the type of each match while workers only know the distribution of $y$ over $\left[y_{L}, y_{H}\right]$. In an online appendix, ${ }^{4}$ we use the demonstration of Menzio (2007) to find the solution of this wage bargain. We show that the equilibrium real wage, whatever the type of the match, is the wage outcome of the Alternating Offers Bargaining (i.e. with perfect information) between a worker and an employer with the lowest match's type, $w_{i}^{A O B}\left(y_{L}\right)$. The average wage for the AOMOSAI is thus:

$\omega_{i}^{A O M O S A I}=w_{i}^{A O B}\left(y_{L}\right)=(1-\beta) z+\beta\left(p_{i}+y_{L}+\gamma\right)$

Since the AOMOSAI combines the Alternating Offers Bargaining and the Asymmetric Information Game, the average wage resulting from this model is less pro-cyclical than the ones resulting from its two components taken in isolation. We have $\omega_{i}^{A O M O S A I}$ less pro-cyclical than $\omega_{i}^{A O B}$, since $\omega_{i}^{A O M O S A I}$ is not affected by the increasing number of matches which realize higher idiosyncratic productivity levels when the aggregate productivity increases. At the same time, we have $\omega_{i}^{A O M O S A I}$ less procyclical than $\omega_{i}^{A I G}$, since the threat points are not the pro-cyclical outside options but instead the a-cyclical disagreement payoffs.

\section{Quantitative analysis}

In this section, we compare the quantitative implications of the four previously described wage specifications. We follow Hall and Milgrom (2008) and Kennan (2010) by evaluating the labor market volatility implied by these specifications from a comparative static exercise that compares steady states at different realizations of $p_{i}$. We assume two states, 1 and 2, with $p_{2}=1.01 p_{1}$ and compute the elasticity of the market tightness with respect to the average productivity. ${ }^{5}$ This elasticity is obtained by setting $\lambda=0$ in Eq. (6) and by dividing the log change in $\theta$ by the log change in $\rho$. We get:

$\epsilon_{\theta}=\frac{d \ln (\theta)}{d \ln (\rho)}=\frac{1}{\eta} \frac{\rho-\epsilon_{\omega} \omega}{\rho-\omega}$

where $\epsilon_{\omega}$ is the elasticity of the average wage with respect to the average productivity, obtained by dividing the log change in $\omega$ by the log change in $\rho$. As argued by Shimer (2005) and Pissarides (2009), this approach is a proper approximation of stochastic simulations if the productivity process is sufficiently persistent, which is the case in Shimer's data.

The wage elasticities for the Nash Bargaining, the Asymmetric Information Game, the Alternating Offers Bargaining and the AOMOSAI are respectively given by:

$\epsilon_{\omega^{N B}}=\frac{d \ln \left(\omega^{N B}\right)}{d \ln (\rho)}=\frac{\beta \rho\left(1+c \frac{d \theta}{d \rho}\right)}{\omega^{N B}}$

$\epsilon_{\omega^{A I G}}=\frac{d \ln \left(\omega^{A I G}\right)}{d \ln (\rho)}=\frac{\beta \rho\left(\frac{d p}{d \rho}+c \frac{d \theta}{d \rho}\right)}{\omega^{A I G}}$

$\epsilon_{\omega^{A O B}}=\frac{d \ln \left(\omega^{A O B}\right)}{d \ln (\rho)}=\frac{\beta \rho}{\omega^{A O B}}$

\footnotetext{
${ }^{4}$ Available upon request to the author.

5 The indicator that received most attention in the literature.
} 
$\epsilon_{\omega^{A O M O S A I}}=\frac{d \ln \left(\omega^{A O M O S A I}\right)}{d \ln (\rho)}=\frac{\beta \rho \frac{d p}{d \rho}}{\omega^{A O M O S A I}}$

where $\frac{d p}{d \rho}$ represents the relative contribution of aggregate shocks to the fluctuations of the average productivity. This ratio only matters for $\epsilon_{\omega^{A I G}}$ and for $\epsilon_{\omega^{A O M O S A I}}$.

\subsection{Calibration}

To compute the various tightness and wage elasticities, we need to set values for the following parameters and steady-state variables: $\rho_{1}$, $y_{L}, p_{1}, \frac{\delta p}{\delta \rho}, \eta, \theta_{1}, \beta, z, c$ and $\gamma$.

Productivity. We normalize $\rho_{1}$ at one and follow Kennan (2010) by assuming that in state 1 , all matches realize $y_{L}$. This implies $\rho_{1}=p_{1}+y_{L}=$ 1 . For the sake of simplicity, we set $y_{L}$ to be $10 \%$ of the average productivity in state 1 , which results in $p_{1}=0.9$ and $y_{L}=0.1$. Note that the assumption that all matches realize $y_{L}$ and the values retained for $p_{1}$ and $y_{L}$ have no impact on the quantitative results. In the data, we observe $\rho_{i}$ and its fluctuations. However, we are not able to distinguish what proportions of these fluctuations are attributable to aggregate shocks and to idiosyncratic shocks since, as Kennan (2010) argues, the latters are privately observed. From the evidence in Dunne et al. (2004) and Kennan (2010) stresses that specific shocks would be moderately procyclical, which would imply a value for $\frac{d p}{d \rho}$ relatively high. At the same time, Atalay (2017) finds that idiosyncratic shocks seem much more volatile than aggregate shocks, which would imply a value for $\frac{d p}{d \rho}$ relatively low. We then set $\frac{d p}{d \rho}$ to 0.5 , at the midpoint between these two results.

Labor market and wage bargaining. The elasticity of the matching function with respect to unemployment, $\eta$, is selected at 0.4 from Blanchard and Diamond (1989). The labor market tightness at state 1, $\theta_{1}$, is set to 0.72 from the evidence in Pissarides (2009). Following a common practice, the worker's bargaining power $\beta$ is chosen at 0.5 , which implies a symmetric bargaining game. We restrict the flow value of unemployment $z$ to unemployment benefits. From Anderson and Meyer (1997) and Mortensen and Nagypál (2007), the after-tax replacement rate is around $30 \%$ in the US, so we set $z=0.3 \omega_{1}$. Two parameters remain to calibrate: the vacancy posting cost, $c$, and the fixed cost incurred by employers during the wage bargaining, $\gamma$. Lacking conventional values for these costs, we proceed as follows. We first note that $\omega_{i}^{N B}$ and $\omega_{i}^{A I G}$ depend on $c$ but are independent from $\gamma$, while $\omega_{i}^{A O B}$ and $\omega_{i}^{A O M O S A I}$ depend on $\gamma$ but are independent from $c$. Moreover, since our calibration for productivity implies $\rho_{1}=p_{1}+y_{L}$, we have $\omega_{1}^{N B}=\omega_{1}^{A I G}=\omega_{1}^{A O B}=\omega_{1}^{A O M O S A I}$ only if $\gamma=c \theta_{1}$. We calibrate $c$ so as to obtain a labor share at the standard value of $70 \%$ for the Nash Bargaining and the Asymmetric Information Game in state 1, i.e. $\omega_{1}^{N B}=\omega_{1}^{A I G}=0.7$. We find $c=0.26$. We then set $\gamma=c \theta_{1}=0.19$, which ensures a labor share at $70 \%$ for the Alternating Offers Bargaining and the AOMOSAI in state 1, i.e. $\omega_{1}^{A O B}=\omega_{1}^{A O M O S A I}=0.7$ (Table 1).

\subsection{Results and assessment}

The empirical tightness elasticity (7.56) is found by Mortensen and Nagypál (2007) and Pissarides (2009), while the empirical wage elasticity (0.45) comes from Hagedorn and Manovskii (2008). All of these data relate to the US economy (Table 2).

The AOMOSAI improves the results on two grounds. First, it considerably amplifies the dynamics of the labor market. Under our calibration, the model replicates $83 \%$ of the observed tightness elasticity. This is $50 \%$ and $79 \%$ greater than what is produced by the Alternating Offers Bargaining and by the Asymmetric Information Game, respectively. This result is related to the higher amount of real wage stickiness generated
Table 1

Parameter and steady-state values.

\begin{tabular}{lll}
\hline Parameters & Values & Target/Mean values/Data \\
\hline$\rho_{1}$ & 1 & Normalization at one \\
$y_{L}$ & 0.1 & Represents 10\% of $\rho_{1}$ \\
$p_{1}$ & 0.9 & No rent in state 1, Kennan (2010) \\
$\frac{\delta p}{\delta \rho}$ & 0.5 & Midpoint between Kennan (2010) and Atalay (2017) \\
$\eta$ & 0.4 & Blanchard and Diamond (1989) \\
$\theta_{1}$ & 0.72 & Pissarides (2009) \\
$\beta$ & 0.5 & Symmetric game \\
$z$ & 0.21 & Replacement rate at 30\% \\
$c$ & 0.26 & Labor share at 70\% for NB and AIG \\
$\gamma$ & 0.19 & Labor share at 70\% for AOB and AOMOSAI \\
\hline
\end{tabular}

Table 2

Tightness and wage elasticities.

\begin{tabular}{|c|c|c|}
\hline & $\begin{array}{l}\text { Tightness elasticity } \\
\epsilon_{\theta}\end{array}$ & $\begin{array}{l}\text { Wage elasticity } \\
\epsilon_{\omega}\end{array}$ \\
\hline Empirical & 7.56 & 0.45 \\
\hline AOMOSAI & 6.25 & 0.36 \\
\hline Alternating Offers Bargaining & 4.17 & 0.71 \\
\hline Asymmetric Information Game & 3.49 & 0.83 \\
\hline Nash Bargaining & 2.33 & 1.00 \\
\hline
\end{tabular}

by the AOMOSAI. Secondly, this model displays a wage elasticity very close to the one found by Hagedorn and Manovskii (2008). It is thus able to replicate the observed rigidity of the real wage and provides an explanation of that rigidity.

Separately, the Alternating Offers Bargaining and the Asymmetric Information Game generate a limited wage stickiness. Hagedorn and Manovskii (2008) demonstrate that what matters for labor-market variability is the response of the profit in percentage terms. To get a responsive profit in proportion, the real wage has to be high and sticky. Given that our calibration targets the US labor share, the resulting equilibrium wage is low. The limited wage rigidity displayed by the Alternating Offers Bargaining and the Asymmetric Information Game therefore necessarily generates a weak tightness elasticity. This explains why Hall and Milgrom (2008) and Kennan (2010) retain high values for the disagreement payoffs. Both papers notably set $z$ at 0.7 . Moreover, Hall and Milgrom calibrate $\gamma$ at 0.27 . The labor shares which stem from these payoffs are close to $100 \%$. Alternatively, additional fixed costs for hiring and training are often assumed to amplify firms' profit responses in proportion. For instance, Mortensen and Nagypál (2007) introduce fixed hiring costs $H$ in the Alternating Offers Bargaining. They show that the resulting framework is able to replicate the tightness elasticity for $z=0.7$ and $H=0.22$. Although lower than in Hall and Milgrom (2008), their labor share is still high (85\%) while Kennan (2010) argues that "the empirical plausibility of the required value for $H$ (about nine months' worth of profits) is questionable". Instead, the AOMOSAI generates a large labormarket volatility for the empirical labor share and does not need any additional cost.

There is still a debate concerning the cyclical behavior of real wages. On one side, Pissarides (2009) reviews a body of studies based on individual data which tend to show that there would be no real wage stickiness. The wage elasticity for new matches, which is the relevant one for job creations, would be equal to 1 . On the other side, Hagedorn and Manovskii (2008) find an elasticity for new matches of 0.45 from both aggregate and individual data. Gertler et al. (2008) show econometrically that the finding of Pissarides (2009) and others is due to a "cyclical composition effect" that biases the results towards more wage flexibility. The wage elasticity estimated for new matches by them and by Gertler and Trigari (2009) is around 0.5. Haefke et al. (2013) estimate a wage elasticity for new matches at 0.83 , but with a standard error of 0.51 that embeds both the value found by Hagedorn and Manovskii (2008) and the one displayed by the AOMOSAI. 


\section{Conclusion}

The Alternating Offers Bargaining and the Asymmetric Information Game provide the main solutions to the unemployment volatility puzzle resting on real wage rigidities. In this paper, we have pointed out that the alternating offers model with one-sided asymmetric information (Grossman and Perry, 1986; Gul and Sonnenschein, 1988; Menzio, 2007), which combines the two frameworks, gives a more satisfactory answer to the puzzle. Separately, each bargaining brings a limited wage stickiness and thus requires very high labor shares and additional hiring costs. The AOMOSAI produces more wage rigidity, which amplifies unemployment responses to aggregate shocks. This model almost completely solves the puzzle for an equilibrium wage that respects the empirical labor share, and without having to assume additional costs. Moreover, the AOMOSAI is capable to display a right amount of wage rigidity and therefore gives a completely micro-founded explanation to the real wage stickiness characterizing labor markets.

\section{References}

Anderson, P., Meyer, B., 1997. Unemployment insurance takeup rates and the after- tax value of benefits. Q. J. Econ. 112 (3), 913-937.

Atalay, E., 2017. How important are sectoral shocks. Am. Econ. J. Macro. Forthcoming. Binmore, K., Rubinstein, A., Wolinsky, A., 1986. The nash bargaining solution in economic modelling. Rand J. Econ. 17 (2), 176-188.

Blanchard, O., Diamond, P., 1989. The beveridge curve. Brookings Pap. Econ. Activity 1, $1-76$.

Dunne, T., Foster, L., Haltiwanger, J., Troske, K., 2004. Wage and productivity dispersion in united states manufacturing: the role of computer investment. J. Labor Econ. 22 (2), 397-430.
Faia, E., Lechthaler, W., Merkl, C., 2014. Labor selection, turnover costs, and optimal monetary policy. J. Money Credit Bank. 46 (1), 115-144.

Gertler, M., Huckfeldt, C., Trigari, A., 2008. Interpreting Wage Cyclicality of New Hire. Mimeo, NYU.

Gertler, M., Trigari, A., 2009. Unemployment fluctuations with staggered nash wage bargaining. J. Polit. Econ. 117 (1), 38-86.

Grossman, S., Perry, M., 1986. Sequential bargaining under asymmetric information. J. Econ. Theory 39 (1), 120-154.

Gul, F., Sonnenschein, H., 1988. On delay in bargaining with one-sided uncertainty. Econometrica 56 (3), 601-611.

Gul, F., Sonnenschein, H., Wilson, R., 1986. Foundations of dynamic monopoly and the coase conjecture. J. Econ. Theory 39, 155-190.

Haefke, C., Sonntag, M., Van Rens, T., 2013. Wage rigidity and job creation. J. Monet. Econ. 60 (8), 887-899.

Hagedorn, M., Manovskii, I., 2008. The cyclical behavior of equilibrium unemployment and vacancies revisited. Am. Econ. Rev. 98 (4), 1692-1706.

Hall, R., Milgrom, P., 2008. The limited influence of unemployment on the wage bargain. Am. Econ. Rev. 98 (4), 1653-1674.

Jung, P., Kuester, K., 2011. The (un)importance of unemployment fluctuations for the welfare cost of business cycles. J. Econ. Dyn. Control 35 (10), 1744-1768.

Kennan, J., 2010. Private information, wage bargaining and employment fluctuations. Rev. Econ. Stud. 77 (2), 633-664.

Menzio, G., 2007. A theory of partially directed search. J. Polit. Econ. 115 (5), 748-769.

Mortensen, D., Nagypál, E., 2007. More on unemployment and vacancy fluctuations. Rev. Econ. Dyn. 10 (3), 327-347.

Myerson, R., 1984. Two-person bargaining problems with incomplete information. Econometrica 52 (2), 461-488.

Pissarides, C., 2009. The unemployment volatility puzzle: is wage stickiness the answer? Econometrica 77, 1339-1369.

Rubinstein, A., 1982. Perfect equilibrium in a bargaining model. Econometrica 50 (1), 97-109.

Shimer, R., 2005. The cyclical behavior of equilibrium unemployment and vacancies. Am. Econ. Rev. 95 (1), 25-49. 